\title{
Demographic stratification of Type 2 diabetes and comorbidities in district healthcare in KwaZulu-Natal
}

\begin{tabular}{|c|c|}
\hline \multicolumn{2}{|c|}{$\begin{array}{l}\text { Authors: } \\
\text { Lauren Chetty }^{1} \text { (D) } \\
\text { Nalini Govender }^{2} \\
\text { Ganesan M. Govender } \\
\text { Poovendhree Reddy }^{3}\end{array}$} \\
\hline \multicolumn{2}{|c|}{$\begin{array}{l}\text { Affiliations: } \\
{ }^{1} \text { Department of Community } \\
\text { Health Studies, Faculty of } \\
\text { Health Sciences, Durban } \\
\text { University of Technology, } \\
\text { Durban, South Africa }\end{array}$} \\
\hline \multicolumn{2}{|c|}{$\begin{array}{l}{ }^{2} \text { Department of Basic Medical } \\
\text { Sciences, Faculty of Health } \\
\text { Sciences, Durban University } \\
\text { of Technology, Durban, } \\
\text { South Africa }\end{array}$} \\
\hline \multicolumn{2}{|c|}{$\begin{array}{l}{ }^{3} \text { General Outpatients } \\
\text { Department, R.K. Khan } \\
\text { Hospital, Durban, } \\
\text { South Africa }\end{array}$} \\
\hline \multicolumn{2}{|c|}{$\begin{array}{l}\text { Corresponding author: } \\
\text { Nalini Govender, } \\
\text { nalinip@dut.ac.za }\end{array}$} \\
\hline \multicolumn{2}{|c|}{$\begin{array}{l}\text { Dates: } \\
\text { Received: } 30 \text { Aug. } 2020 \\
\text { Accepted: } 20 \text { Dec. } 2020 \\
\text { Published: } 20 \text { Apr. } 2021\end{array}$} \\
\hline \multicolumn{2}{|c|}{$\begin{array}{l}\text { How to cite this article: } \\
\text { Chetty L, Govender N, } \\
\text { Govender GM, Reddy P. } \\
\text { Demographic stratification } \\
\text { of Type } 2 \text { diabetes and } \\
\text { comorbidities in district } \\
\text { healthcare in KwaZulu- } \\
\text { Natal. S Afr Fam Pract. } \\
\text { 2021;63(1), a5218. } \\
\text { https://doi.org/10.4102/ } \\
\text { safp.v63i1.5218 }\end{array}$} \\
\hline \multicolumn{2}{|c|}{$\begin{array}{l}\text { Copyright: } \\
\text { (C) 2021. The Authors. } \\
\text { Licensee: AOSIS. This work } \\
\text { is licensed under the } \\
\text { Creative Commons } \\
\text { Attribution License. }\end{array}$} \\
\hline Read online: & \\
\hline 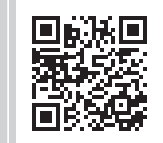 & $\begin{array}{l}\text { Scan this QR } \\
\text { code with your } \\
\text { smart phone or } \\
\text { mobile device } \\
\text { to read online. }\end{array}$ \\
\hline
\end{tabular}

Background: Diabetes has been reported as the second leading cause of death and the top leading cause of death amongst women in South Africa; it is important to evaluate any epidemiological or demographic transition related to diabetes. This study evaluated the demographically stratified prevalence of type 2 diabetes mellitus (T2DM) and existing comorbidities amongst an outpatient population in a district healthcare facility in Kwazulu-Natal (KZN).

Methods: This retrospective cross-sectional study was conducted at a district hospital, and a retrospective record review of all outpatients who reported to the hospital to be treated for T2DM between the period, August 2018-January 2019, was used. Data, such as age, sex, ethnicity and any coexisting morbidity, were collected from outpatient hospital registers and electronically captured using a record review tool.

Results: There were significantly more female patients (3072) compared to male patients (1050) $(p<0.001)$ with a mean age of 59.21 years. Hypertension $(77.9 \%)$ and cardiovascular problems (11.16\%) were most frequent. Approximately $84 \%$ of women presented with T2DM and either one or two morbidities simultaneously. Female patients were at significantly higher risk of presenting with hypertension (odds ratio $[\mathrm{OR}]=1.44$, 95\% confidence interval [CI]: 1.20;1.71), whilst their risk for cardiovascular problems was significantly lower compared to male patients (OR $=0.67,95 \% \mathrm{CI}: 0.54 ; 0.83$ ).

Conclusion: The prevalence of T2DM and comorbidities differed by demographic factors, such as sex, ethnicity and age. There is a need for flexible and adaptive approaches for the prevention and management of T2DM cases in order to allocate medical resources efficiently and according to the true burden of disease because of T2DM complications.

Keywords: type 2 diabetes mellitus; demographics; comorbidities; prevalence; healthcare; non-communicable diseases; epidemiology; disease burden.

\section{Background}

The International Diabetes Federation (IDF) estimates that 693 million adults will be living with diabetes mellitus (DM) by $2045 .{ }^{1}$ It is predicted that by 2030 , developing countries will experience as much as a $69 \%$ increase in new diagnoses. ${ }^{2}$ South Africa (SA) is particularly vulnerable to this epidemic given the increase in urbanisation, prevalence of obesity and physical inactivity and the strained healthcare system already burdened by communicable diseases, such as human immunodeficiency virus (HIV) and tuberculosis (TB). ${ }^{3}$ It is imperative to continue tracking both the prevalence and incidence of type 2 diabetes mellitus (T2DM), given the impact on healthcare resources and the implications for the emerging SA National Health Insurance (NHI) policy. Type 2 diabetes mellitus was reported to be the fifth leading cause of death in 2012-2013 (4.4\% - 4.8\%) and was ranked as the second leading cause of death for women. ${ }^{4}$ Barely 2 years later (2015-2016), it is the overall second leading cause of death $(5.4 \%-5.6 \%)$ and ranked as the top leading cause of death amongst women (7.2\%). ${ }^{4}$ District Health Information System (DHIS) data showed that the provincial crude prevalence of T2DM in KwaZulu-Natal (KZN) was $12.5 \%$ which increased to $34.1 \%$ when patients with private medical aid and undiagnosed T2DM were considered. ${ }^{5}$ Risk factors linked to T2DM are extensively reported. ${ }^{6,7}$ However, it is important to evaluate any demographic transition related to T2DM, particularly for mitigation and management. 
In SA, there was a $5.5 \%$ increase in the prevalence of T2DM amongst people aged 30 years and older between 2000 and 2012. ${ }^{8}$ Likewise, in Africa, the prevalence is increased amongst people aged between 40 and 60 years in contrast to those older than 60 years. ${ }^{9}$ Sub-Saharan African (SSA) studies demonstrated a peak prevalence in the oldest age group (> 65 years), ${ }^{10,11,12}$ in contrast to others who showed a peak prevalence in the $45-64$ years age group..$^{13,14,15}$ From global estimates, it is likely that the male excess previously reported for SSA is likely to increase by $2025 .{ }^{16}$ However, it is evident from available data that the gender distribution varies between and within populations with no obvious trend..$^{17}$ Ethnicity and genetic history have been reported as a significant risk factor in T2DM. ${ }^{18}$ Asians are reported to have an increased susceptibility for $\mathrm{T}_{2 \mathrm{DM}},{ }^{19}$ which may be similar for SA Indians. Moreover, this T2DM incidence may be increasing amongst Africans as a result of increasing urbanisation and socio-economic conditions coupled with poor nutritional choices. ${ }^{9}$ An evaluation of demographic data associated with the incidence and prevalence of T2DM is essential in advancing the precision in the prediction of incidence, complications, mortality and frequency of atypical variants. ${ }^{20}$

Previous studies suggest that chronic complications presented with T2DM reduce the quality of life, increase diabetes-related mortality and pose a significant healthcare burden..$^{21,22}$ The spectrum of various comorbidities linked with T2DM requires correct management and is critical in African countries, including South Africa, where limited healthcare resources require strategic allocation. T2DMrelated comorbidities include micro- or macro-vascular complications, such as cardiovascular diseases, blindness, peripheral neuropathy and kidney disease, ${ }^{23}$ which subsequently increases the risk of strokes, heart attacks and amputations. ${ }^{24}$ Other conditions include adverse oral health, arthritis, vision-related issues, depression, slow wound healing, fatigue and hypoglycaemic episodes. ${ }^{25}$ Diabetics may present with several of the above conditions simultaneously, contributing to increased mortality and morbidity. ${ }^{23,26}$ In addition, demographic factors, such as age, sex and ethnicity, should be considered in relation to comorbidities, given that South Africa is facing an increased burden of non-communicable diseases. ${ }^{27} \mathrm{KwaZulu-Natal} \mathrm{has}$ the largest population of Indians and the highest reported $\mathrm{HIV}$ and $\mathrm{TB}$ prevalence in $\mathrm{SA},{ }^{5}$ predisposing them to increased susceptibility. This study included a retrospective assessment of patients who attended a regional hospital in the EThekwini district (KZN,SA), with the aim of determining the demographic prevalence of T2DM and existing comorbidities.

\section{Methods and materials Study design and site}

This retrospective study was conducted at a district hospital located in the eThekwini health district. The hospital has a catchment population of over 1500000 people who are amongst the poorest in the eThekwini district. The hospital has approximately 36000 admissions in a year, and 600000 outpatients are treated annually. ${ }^{28}$ It serves a population of approximately 240000 .

\section{Study population and sampling strategy}

All outpatients who were treated for T2DM between the period August 2018 and January 2019 were included in the study. Permission was sought from the Department of Health and hospital management to conduct the study. Once permission was received, a retrospective review on hospital registers for the 6-month period was carried out to determine the prevalence of T2DM. Data, such as age, gender and ethnicity, were collected and electronically captured using a data capturing tool.

\section{Inclusion criteria}

All participants who were:

- treated with T2DM within the 6 months (Aug 2018 Jan 2019) under study

- reported to R.K. Khan Hospital for chronic treatment for T2DM.

\section{Exclusion criteria}

- Type 1 diabetes

- Gestational diabetes

\section{Data collection}

A retrospective record review of all outpatients who attended the DM clinic in the hospital for chronic treatment between the period August 2018 and January 2019 was conducted. Data, such as age, sex, ethnicity and any coexisting morbidity, were collected from outpatient hospital registers (paper-based) for a period of 6 months and electronically captured using a record review tool. Data were limited by the information available in the hospital register; demographic variables such as gender, age and ethnicity were available. Clinical data included a record of specific comorbidities such as hypertension, cardiac problems, epilepsy, asthma, arthritis, anaemia and mental health. Cardiovascular problems included congenital heart disease, coronary artery disease, heart failure, heart attack, heart valve disease, cardiomyopathy, atherosclerosis and ischemic heart disease. However, clinical data for other related T2DM-associated morbidities (e.g. oral, ocular and foot ulcers) were not available from the outpatient registers.

\section{Data analysis}

Data were captured using Microsoft Excel using double entry procedures, cleaned through range checking and spot checking and coded for data analysis. Data were analysed using STATA version 12 (Statacorp). Descriptive statistics included frequency counts, percentages, mean and standard deviation. T2DM cases from the hospital register were stratified by ethnicity, age and gender to determine 
the demographic profile. A test of proportions was used to evaluate differences between demographic variables and sex. Patients with early onset DM were defined as those patients who were first diagnosed with DM before 45 years old. Age was dichotomised by sex, ethnicity and pre-existing comorbidities as both a continuous and categorical variable. The $t$-test was used for comparison of age stratified by sex and pre-existing comorbidities, whilst the chi-squared test of proportions was used to compare T2DM stratified by sex, ethnicity, age and comorbidities. A variable was created to represent the total number of pre-existing comorbidities for each patient as reflected in the hospital register. Multivariate logistic regression models, adjusted for age, were run using the comorbidity as the dependent variable and gender and ethnicity as the independent variables. In addition, we used the frequency of pre-existing comorbidities as a dependent variable with sex and ethnicity as the independent variables. A 95\% confidence interval (CI) was reported and $p \leq 0.05$ was considered statistically significant.

\section{Ethical considerations}

The study was approved by the Durban University of Technology Institutional Research Ethics Committee (IREC) (REC 112/19) and the KwaZulu-Natal Department of Health.

\section{Results}

A total of $4122(N)$ outpatients were presented with T2 DM between August 2018 and January 2019 at the district hospital. There were significantly more female patients (3072) compared to male patients $(1050)(p<0.001)$ with a mean age of 59.21 years (Table 1$)$. Overall, approximately $10 \%$ of patients were presented with early onset DM ( $<45$ years old), affecting significantly more women than men (309 vs. 132). Most of the new cases presenting with T2DM over the 6-month period were between 55 years and 64 years old $(31.59 \%)$ with $77.42 \%$ of all outpatients between the ages of 45 years and 74 years (Table 1 ). Diabetic outpatients seeking treatment at the hospital dropped from 644 in August 2018 to 584 in September 2018. A marked increase was noted between October (834) and November (1222), with fewer patients in December (408) and January (429). This reduction may be related to the poor access during the holiday season.

A total of 1514 (36.73\%) African and 2493 (60.48\%) Indian (South Asian) patients were included for further demographic stratification (Table 2). There was comparatively fewer mixed race and white (Caucasians) patients compared to African and Indian patients (South Asian), so they were excluded from further bivariate and multivariate analysis. Because of low numbers, mixed race and white patients were excluded from further analysis. Significantly, more Indian female patients were presented with T2DM compared with African female patients $(p<0.05)$. Similarly, more Indians were presented with T2DM in each age category compared to Africans. However, the early onset of T2DM was similar between African and Indian patients (214 and 215, respectively).

The categorised prevalence of comorbidities is presented in Table 3. Hypertension (3212) and cardiovascular problems (460) were most frequent, with a prevalence of $77.9 \%$ and $11.16 \%$, respectively. Approximately 40\% (176/441) of patients with early onset DM also suffered with hypertension. The prevalence of comorbidities, such as hypertension, arthritis and anaemia, was significantly higher amongst female patients than in male patients. Whilst cardiovascular problems were significantly higher for Indians compared to Africans $(67 \%$ vs. $28 \%, p<0.05)$, the converse was true for epilepsy and mental health. The likelihood of presenting with comorbidities increased significantly with age, as most patients aged between 55 and 74 years presented with hypertension, cardiovascular problems and arthritis $(p<0.05)$.

TABLE 1: Age profile of type 2 diabetes mellitus patients presenting at the district hospital stratified by sex.

\begin{tabular}{|c|c|c|c|c|c|c|c|}
\hline \multirow[t]{2}{*}{ Demographic } & \multicolumn{2}{|c|}{ Total } & \multicolumn{2}{|c|}{ Male } & \multicolumn{2}{|c|}{ Female } & \multirow[t]{2}{*}{$p^{*}$} \\
\hline & $n$ & $\%$ & $n$ & $\%$ & $n$ & $\%$ & \\
\hline Total & 4122 & 100.00 & 1050 & 25.47 & 3072 & 74.53 & $<0.005$ \\
\hline Age (mean, SD) & 59.21 & 12.84 & 57.92 & 12.68 & 59.66 & 12.86 & 0.245 \\
\hline Early onset $\mathrm{DM} \dagger$ & 441 & 10.70 & 132 & 12.57 & 309 & 10.06 & 0.012 \\
\hline \multicolumn{8}{|c|}{ Age category (years) } \\
\hline $0-15$ & 15 & 0.36 & 4 & 0.38 & 11 & 0.36 & 0.016 \\
\hline $15-24$ & 44 & 1.07 & 14 & 1.33 & 30 & 0.98 & $<0.005$ \\
\hline $25-34$ & 98 & 2.38 & 27 & 2.57 & 71 & 2.31 & $<0.005$ \\
\hline $35-44$ & 284 & 6.89 & 87 & 8.29 & 197 & 6.41 & $<0.005$ \\
\hline $45-54$ & 972 & 23.58 & 266 & 25.33 & 706 & 22.98 & $<0.005$ \\
\hline $55-64$ & 1302 & 31.59 & 345 & 32.86 & 957 & 31.15 & $<0.005$ \\
\hline $65-74$ & 917 & 22.25 & 209 & 19.90 & 708 & 23.05 & $<0.005$ \\
\hline $75-84$ & 451 & 10.94 & 92 & 8.76 & 359 & 11.69 & $<0.005$ \\
\hline 85-98 & 39 & 0.95 & 6 & 0.57 & 33 & 1.07 & $<0.005$ \\
\hline
\end{tabular}

$N=4122$.

$\mathrm{SD}$, standard deviation; DM, diabetes mellitus.

$*, p<0.05$ was considered statistically significant.

$\dagger$, Early onset DM includes all patients who were first diagnosed with diabetes when they were $<45$ years old. 
TABLE 2: Ethnicity-stratified demographic characterisation of all patients with type 2 diabetes mellitus.

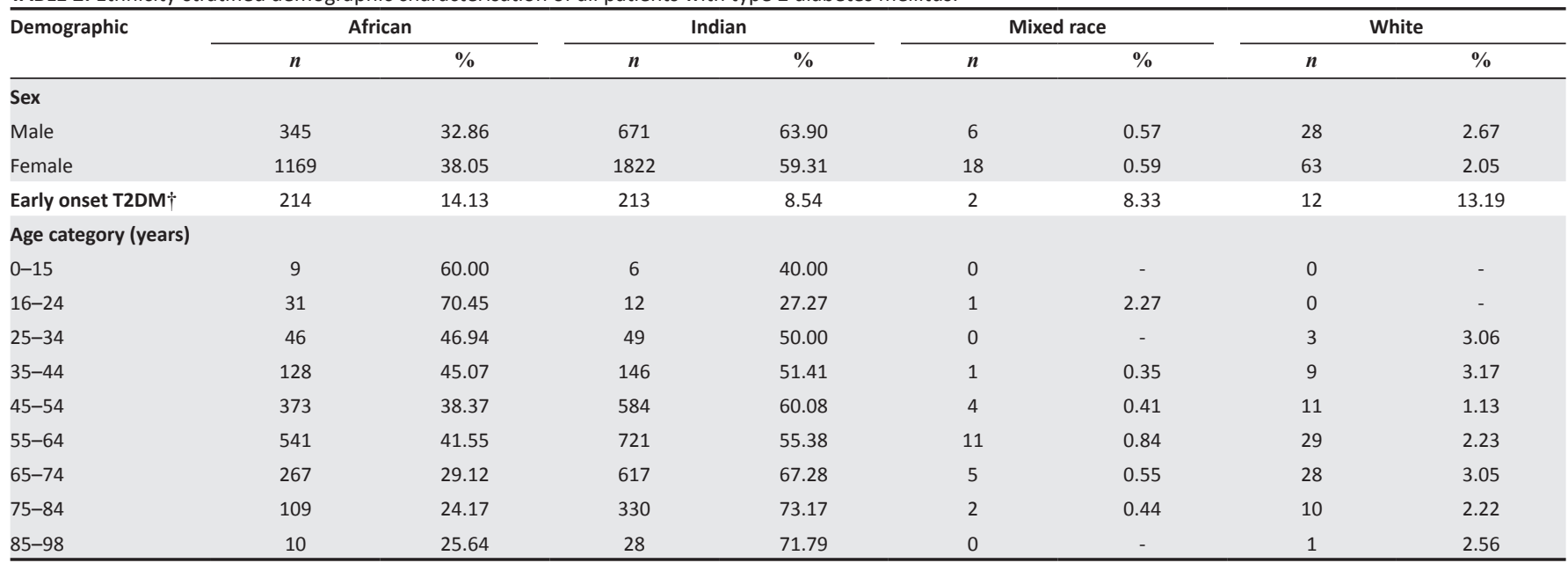

$N=4122$.

T2DM, type 2 diabetes mellitus.

$\dagger$, Early onset DM includes all patients who were first diagnosed with diabetes when they were $<45$ years old.

TABLE 3: Existing comorbidities amongst patients with type 2 diabetes mellitus.

\begin{tabular}{|c|c|c|c|c|c|c|c|c|c|c|c|c|c|c|c|c|}
\hline \multirow[t]{2}{*}{ Comorbidities } & \multicolumn{2}{|c|}{ Hypertension } & \multicolumn{2}{|c|}{ Cardiac } & \multicolumn{2}{|c|}{ Epilepsy } & \multicolumn{2}{|c|}{ Asthma } & \multicolumn{2}{|c|}{ Arthritis } & \multicolumn{2}{|c|}{ Anaemia } & \multicolumn{2}{|c|}{ Mental health } & \multicolumn{2}{|c|}{ TB } \\
\hline & $n$ & $\%$ & $n$ & $\%$ & $n$ & $\%$ & $n$ & $\%$ & $n$ & $\%$ & $n$ & $\%$ & $n$ & $\%$ & $n$ & $\%$ \\
\hline Total & 3212 & 77.92 & 460 & 11.16 & 99 & 2.40 & 207 & 5.02 & 245 & 5.94 & 118 & 2.86 & 116 & 2.81 & 59 & 1.43 \\
\hline \multicolumn{17}{|l|}{ Sex } \\
\hline Male & 761 & 23.69 & 313 & 68.04 & 30 & 30.30 & 48 & 23.19 & 33 & 13.47 & 15 & 12.71 & 33 & 28.45 & 12 & 20.34 \\
\hline Female & 2451 & 76.31 & 147 & 31.96 & 69 & 69.70 & 159 & 76.81 & 212 & 86.53 & 103 & 87.29 & 83 & 71.55 & 47 & 79.66 \\
\hline$p^{*}$ & $<0.005$ & - & $<0.001$ & - & 0.264 & - & 0.439 & - & $<0.005$ & - & $<0.001$ & - & 0.456 & - & 0.362 & - \\
\hline \multicolumn{17}{|l|}{ Race } \\
\hline African & 1149 & 35.77 & 130 & 28.26 & 53 & 53.54 & 46 & 22.22 & 107 & 43.67 & 36 & 30.51 & 53 & 45.69 & 27 & 45.76 \\
\hline Indian & 1976 & 61.52 & 309 & 67.17 & 43 & 43.43 & 151 & 72.95 & 134 & 54.69 & 82 & 69.49 & 55 & 47.41 & 31 & 52.54 \\
\hline$p^{*}$ & 0.085 & - & $<0.005$ & - & $<0.004$ & - & $<0.005$ & - & 0.105 & - & 0.098 & - & $<0.004$ & - & 0.208 & - \\
\hline Early onset DM & 176 & 40.00 & 21 & 4.76 & 8 & 1.81 & 24 & 5.44 & 9 & 2.04 & 10 & 2.27 & 8 & 1.81 & 3 & 0.68 \\
\hline \multicolumn{17}{|c|}{ Age category (years) } \\
\hline $0-15$ & 1 & 0.03 & 1 & 0.22 & - & - & - & - & - & - & - & - & - & - & - & - \\
\hline $15-24$ & 9 & 0.28 & 1 & 0.22 & - & - & - & - & - & - & - & - & 3 & 2.59 & - & - \\
\hline $25-34$ & 30 & 0.93 & 2 & 0.43 & - & - & 3 & 1.45 & - & - & 3 & 2.54 & 1 & 0.86 & - & - \\
\hline $35-44$ & 136 & 4.23 & 17 & 3.70 & 8 & 8.08 & 21 & 10.14 & 9 & 3.67 & 7 & 5.93 & 4 & 3.45 & 3 & 5.08 \\
\hline $45-54$ & 710 & 22.10 & 90 & 19.57 & 26 & 26.26 & 53 & 25.60 & 55 & 22.45 & 30 & 25.42 & 30 & 25.86 & 17 & 28.81 \\
\hline $55-64$ & 1090 & 33.94 & 137 & 29.78 & 43 & 43.43 & 67 & 32.37 & 103 & 42.04 & 27 & 22.88 & 35 & 30.17 & 24 & 40.68 \\
\hline $65-74$ & 799 & 24.88 & 141 & 30.65 & 10 & 10.10 & 44 & 21.26 & 52 & 21.22 & 35 & 29.66 & 27 & 23.28 & 8 & 13.56 \\
\hline $75-84$ & 405 & 12.61 & 68 & 14.78 & 11 & 11.11 & 17 & 8.21 & 26 & 10.61 & 14 & 11.86 & 16 & 13.79 & 7 & 11.86 \\
\hline 85-100 & 32 & 1.00 & 3 & 0.65 & 1 & 1.01 & 2 & 0.97 & - & - & 2 & 1.69 & - & - & - & - \\
\hline$p$ & $<0.005$ & - & $<0.005$ & - & $<0.048$ & - & 0.321 & - & $<0.001$ & - & 0.358 & - & 0.374 & - & 0.487 & - \\
\hline
\end{tabular}

$N=4007$.

DM, diabetes mellitus; TB, tuberculosis

$*, p<0.05$ was considered statistically significant.

When logistic regression was applied using sex and ethnicity (African and Indian) as independent variables, female patients with T2DM were at significantly higher risk of presenting with hypertension (odds ratio [OR] $=1.44,95 \%$ CI:1.20;1.71), arthritis (OR $=2.20,95 \% \mathrm{CI}: 1.51 ; 3.20)$ and anaemia $(\mathrm{OR}=2.42,95 \% \mathrm{CI}: 1.40 ; 4.19)$, whilst their risk for cardiovascular problems was significantly lower compared to male patients $(\mathrm{OR}=0.67,95 \% \mathrm{CI}$ : 0.54;0.83). Age-adjusted regression also illustrated a higher risk for cardiovascular problems and asthma amongst Indians with T2DM, with a lower risk for epilepsy, arthritis, and mental health-related problems compared to Africans (Table 4). Table 5 illustrates the number of co-existing morbidities stratified by gender, ethnicity and age. Overall, only 621 (15\%) patients had no comorbidity, whilst 2522 (61\%) patients suffered at least one diagnosed condition. Hospital registers demonstrated more comorbidities for women compared to men $(p<0.05)$, with $84 \%$ (2574/3072) women presenting with T2DM and either 1 or 2 morbidities simultaneously. For both sexes, it was observed that DM plus one comorbidity was the most common combination. Indians presented with significantly more comorbidities than Africans. When the presence of multiple morbidities was further stratified by sex, significantly more Indian male patients presented with $\mathrm{DM}+1$ morbidity compared to African male patients $(p<0.005)$. Similar results with respect to ethnicity were 
TABLE 4: Logistic regression analysis of comorbidities presented by patients with type 2 diabetes mellitus.

\begin{tabular}{|c|c|c|c|c|c|}
\hline \multirow[t]{2}{*}{ Existing comorbidity } & \multicolumn{2}{|c|}{ Female } & \multicolumn{2}{|c|}{ Indian } & \multirow[t]{2}{*}{$p$} \\
\hline & OR & $95 \% \mathrm{Cl}$ & OR & $95 \% \mathrm{Cl}$ & \\
\hline Hypertension & 1.44 & $1.20 ; 1.71$ & 1.01 & $0.85 ; 1.20$ & $<0.005$ \\
\hline Cardiac & 0.67 & $0.54 ; 0.83$ & 1.35 & $1.09 ; 1.68$ & $<0.001$ \\
\hline Epilepsy & 0.76 & $0.48 ; 1.18$ & 0.48 & $0.32 ; 0.73$ & 0.264 \\
\hline Asthma & 1.15 & $0.82 ; 1.62$ & 2.11 & $1.50 ; 2.96$ & 0.439 \\
\hline Arthritis & 2.20 & $1.51 ; 3.20$ & 0.77 & $0.59 ; 0.10$ & $<0.005$ \\
\hline Anaemia & 2.42 & $1.40 ; 4.19$ & 1.44 & $0.97 ; 2.14$ & $<0.001$ \\
\hline Mental health & 0.82 & $0.54 ; 1.25$ & 0.62 & $0.42 ; 0.90$ & 0.456 \\
\hline TB & 1.28 & $0.68 ; 2.43$ & 0.70 & $0.42 ; 1.18$ & 0.362 \\
\hline
\end{tabular}

Note: Models were adjusted for age. Male patients and African patients were the reference categories.

$N=4022$.

TB, tuberculosis; OR, odds ratio; $95 \% \mathrm{Cl}, 95 \%$ confidence interval.

$*, p<0.001 ; * *, p<0.05$.

TABLE 5: Type 2 diabetes mellitus patients stratified by frequency of comorbidities.

\begin{tabular}{|c|c|c|c|c|c|c|c|c|c|c|}
\hline \multirow[t]{3}{*}{ Demographics } & \multicolumn{10}{|c|}{ Frequency of co-existing morbidities } \\
\hline & \multicolumn{2}{|c|}{ DM only $\dagger$} & \multicolumn{2}{|c|}{$\mathrm{DM}+1$} & \multicolumn{2}{|c|}{$\mathrm{DM}+2$} & \multicolumn{2}{|c|}{$\mathrm{DM}+3$} & \multicolumn{2}{|c|}{$\mathrm{DM}+4$} \\
\hline & $n$ & $\%$ & $n$ & $\%$ & $n$ & $\%$ & $n$ & $\%$ & $n$ & $\%$ \\
\hline Total & 621 & 15.07 & 2522 & 61.18 & 878 & 21.30 & 92 & 2.23 & 9 & 0.22 \\
\hline \multicolumn{11}{|l|}{ Sex } \\
\hline Male & 208 & 33.55 & 605 & 23.99 & 221 & 25.17 & 16 & 17.39 & - & - \\
\hline Female & 412 & 66.45 & 1917 & 76.01 & 657 & 74.83 & 76 & 82.61 & 9 & 100.00 \\
\hline$p$ & $<0.005$ & - & $<0.005$ & - & $<0.005$ & - & $<0.000$ & - & $<0.002$ & - \\
\hline \multicolumn{11}{|l|}{ Race } \\
\hline African & 254 & 42.12 & 914 & 37.17 & 312 & 36.84 & 29 & 32.95 & 4 & 44.44 \\
\hline Indian & 349 & 57.88 & 1545 & 62.83 & 535 & 63.16 & 59 & 67.05 & 5 & 55.56 \\
\hline$p$ & $<0.005$ & - & $<0.005$ & - & $<0.005$ & - & $<0.001$ & - & 0.739 & - \\
\hline Early onset DM $\ddagger$ & 227 & 36.55 & 164 & 6.50 & 44 & 5.01 & 5 & 5.43 & 1 & 1.11 \\
\hline \multicolumn{11}{|c|}{ Age category (years) } \\
\hline $0-15$ & 13 & 2.10 & 2 & 0.08 & - & - & - & - & - & - \\
\hline $25-34$ & 62 & 10.00 & 30 & 1.19 & 4 & 0.46 & 1 & 1.09 & - & - \\
\hline $35-44$ & 119 & 19.19 & 121 & 4.80 & 40 & 4.56 & 3 & 3.26 & 1 & 11.11 \\
\hline $45-54$ & 170 & 27.42 & 597 & 23.67 & 187 & 21.30 & 15 & 16.30 & 3 & 33.33 \\
\hline $55-64$ & 125 & 20.16 & 845 & 33.51 & 291 & 33.14 & 39 & 42.39 & 2 & 22.22 \\
\hline $65-74$ & 67 & 10.81 & 592 & 23.47 & 240 & 27.33 & 15 & 16.30 & 3 & 33.33 \\
\hline $75-84$ & 28 & 4.52 & 294 & 11.66 & 112 & 12.76 & 17 & 18.48 & - & - \\
\hline $85-98$ & 4 & 0.65 & 30 & 1.19 & 4 & 0.46 & 1 & 1.09 & - & - \\
\hline
\end{tabular}

$N=4022$.

DM, diabetes mellitus.

$*, p<0.05$ was considered statistically significant.

$\dagger$, patients presenting with only DM; DM+1: patients presenting with DM and 1 comorbidity; DM+2: patients presenting with DM and 2 comorbidities; $D M+3$ : patients presenting with DM and 3 comorbidities; DM+4: patients presenting with DM and 4 comorbidities

$\$$, Early onset DM includes all patients under 45 years.

obtained for all other categories of frequency of comorbidities when stratified by sex and age category (Table 6).

Age-adjusted regression analysis was done using sex and ethnicity as independent variables (Table 7). The logit estimate for female patients relative to male patients was significantly lower $(\beta=-0.42,95 \% \mathrm{CI}:-0.62 ;-0.21)$ for presenting with DM only compared to DM + 1 comorbidity $(p<0.001)$, which indicates that male patients are more likely than female patients to present with DM only. None of the other regression analyses using sex and ethnicity were statistically significant.

\section{Discussion}

This study demonstrates the demographically stratified prevalence of T2DM and existing comorbidities amongst an outpatient population in a district healthcare facility in KZN. Our data highlight that more women than men present with T2DM and one or more of the existing comorbidities. Even though all reported existing morbidities are not directly linked with T2DM, it impacts on healthcare resources, particularly for treatment modalities. Moreover, this was shown to be significantly influenced by demographic factors such as sex, ethnicity and age. Indians were overrepresented in the population under study, and logistic regression showed a greater risk of disease burden amongst Indians compared to Africans, particularly with respect to hypertension. The high burden of T2DM and hypertension as coexisting morbidities $(77.9 \%)$ and the $10 \%$ prevalence of early onset $\mathrm{DM}$ (patients $<45$ years) should be noted as serious concerns in an epidemiological transition in SA where noncommunicable diseases (NCDs) are increasingly prevalent. 
TABLE 6: Demographic profile of type 2 diabetes mellitus patients stratified by frequency of comorbidities.

\begin{tabular}{|c|c|c|c|c|c|c|c|c|c|c|c|c|c|c|c|c|}
\hline \multirow[t]{3}{*}{ Demographics } & \multicolumn{8}{|c|}{ African } & \multicolumn{8}{|c|}{ Indian } \\
\hline & \multicolumn{2}{|c|}{$\mathrm{DM}+1$} & \multicolumn{2}{|c|}{$\mathrm{DM}+2$} & \multicolumn{2}{|c|}{$\mathrm{DM}+3$} & \multicolumn{2}{|c|}{$\mathrm{DM}+4$} & \multicolumn{2}{|c|}{$\mathrm{DM}+1$} & \multicolumn{2}{|c|}{$\mathrm{DM}+2$} & \multicolumn{2}{|c|}{$\mathrm{DM}+3$} & \multicolumn{2}{|c|}{$\mathrm{DM}+4$} \\
\hline & $n$ & $\%$ & $n$ & $\%$ & $n$ & $\%$ & $n$ & $\%$ & $n$ & $\%$ & $n$ & $\%$ & $n$ & $\%$ & $n$ & $\%$ \\
\hline \multicolumn{17}{|l|}{ Sex } \\
\hline Male & 187 & $31.75 *$ & 69 & 32.39 & 6 & 40.00 & 1 & - & 402 & $68.25 *$ & 144 & 67.61 & 9 & 60.00 & - & - \\
\hline Female & 727 & 38.88 & 243 & 38.33 & 23 & 31.51 & 4 & 44.44 & 1143 & 61.12 & 391 & 61.67 & 50 & 68.49 & 5 & 55.56 \\
\hline Early onset $\mathrm{DM} \dagger$ & 75 & 35.05 & 20 & 9.35 & 2 & 0.93 & - & - & 83 & 38.97 & 23 & 10.80 & 3 & 1.41 & 1 & 0.47 \\
\hline \multicolumn{17}{|c|}{ Age category (years) } \\
\hline $0-15$ & 2 & 100.00 & - & - & - & - & - & - & - & - & - & - & - & - & - & - \\
\hline $16-24$ & 7 & 63.64 & - & - & - & - & - & - & 4 & 36.36 & - & - & 1 & 100.00 & - & - \\
\hline $25-34$ & 12 & 41.38 & 2 & 50.00 & 1 & 100.00 & - & - & 17 & 58.62 & 2 & 50.00 & - & - & - & - \\
\hline $35-44$ & 54 & 46.55 & 18 & 46.15 & 1 & 33.33 & - & - & 62 & 53.45 & 21 & 53.85 & 2 & 66.67 & 1 & 100.00 \\
\hline $45-54$ & 225 & 38.59 & 87 & 46.52 & 7 & 46.69 & 1 & 33.33 & 358 & 61.41 & 100 & 53.48 & 8 & 53.33 & 2 & 6.67 \\
\hline $55-64$ & 354 & 42.86 & 117 & 42.09 & 15 & 41.67 & 2 & 100.00 & 472 & 57.14 & 161 & 57.91 & 21 & 58.33 & - & - \\
\hline $65-74$ & 178 & 30.96 & 66 & 29.07 & 2 & 14.29 & 1 & 33.33 & 397 & 69.04 & 161 & 70.93 & 12 & 85.71 & 2 & 6.67 \\
\hline $85-98$ & 8 & 27.59 & - & - & - & - & - & - & 21 & 72.41 & 4 & 100.00 & 1 & 100.00 & - & - \\
\hline
\end{tabular}

$\mathrm{DM}$ only: patients presenting with only $\mathrm{DM}$; $\mathrm{DM}+1$ : patients presenting with $\mathrm{DM}$ and 1 comorbidity; $\mathrm{DM}+2$ : patients presenting with $\mathrm{DM}$ and 2 comorbidities; $\mathrm{DM}+3$ : patients presenting with $\mathrm{DM}$ and 3 comorbidities; $\mathrm{DM}+4$ : patients presenting with $\mathrm{DM}$ and 4 comorbidities.

$N=4122$.

$\mathrm{DM}$, diabetes mellitus.

$*, p<0.001 ; * *, p<0.05 ; * * *, p<0.005$.

$\dagger$, Early onset DM includes all patients under 45 years.

TABLE 7: Regression analysis of the number of comorbidities (frequency) stratified by sex and ethnicity.

\begin{tabular}{|c|c|c|c|c|}
\hline \multirow[t]{2}{*}{ Frequency of comorbidities $\dagger$} & \multicolumn{2}{|c|}{ Female } & \multicolumn{2}{|c|}{ Indian } \\
\hline & $\beta$-coeff & $95 \% \mathrm{Cl}$ & $\beta$-coeff & $95 \% \mathrm{Cl}$ \\
\hline DM only & $-0.42 *$ & $-0.62 ;-0.21$ & 0.06 & $-0.13 ; 0.25$ \\
\hline $\mathrm{DM}+2$ & -0.07 & $-0.25 ; 0.10$ & -0.01 & $-0.18 ; 0.15$ \\
\hline $\mathrm{DM}+3$ & 0.4 & $-0.15 ; 0.95$ & -0.2 & $-0.28 ; 0.63$ \\
\hline
\end{tabular}

Note: Reference categories were male patients and African patients.

DM, diabetes mellitus; $95 \% \mathrm{Cl}, 95 \%$ confidence interval.

$*, p<0.001$.

$\dagger$, The frequency of DM +1 comorbidity was the base outcome. $D M+4$ was excluded because of low frequency.

$\$$, Patients presenting with only DM; $D M+1$ : patients presenting with $D M$ and 1 comorbidity; $D M+2$ : patients presenting with $D M$ and 2 comorbidities; $D M+3$ : patients presenting with $D M$ and 3 comorbidities; $\mathrm{DM}+4$ : patients presenting with $\mathrm{DM}$ and 4 comorbidities.

T2DM prevalence has been reported in several studies conducted in South Africa; ${ }^{24,29}$ however, incidence data have been limited. Despite the recent reporting incidence of DM for 11 districts in KZN by Sahadew et al., ${ }^{5}$ the data are limited in which only DHIS data were used. District Health Information Systems data contain patient visits for T2DM treatment aggregated per healthcare facility and exclude individual patient tracking through identifiers. Thus, it may be possible that a single patient could be counted several times as patients may report to the facility on a monthly basis to collect their medication. This study presents T2DM patients who were given unique hospital identifiers at their first visit for treatment. Moreover, we chose a 6-month period as some diabetics would only see a doctor once every 6 months, whilst continuing to collect their chronic medication at an affiliated clinic.

Our data revealed a significantly higher prevalence of T2DM amongst female patients in contrast to male patients, irrespective of age and sex. This may be associated with sociocultural factors such as varying behavioural patterns between male patients and female patients which influences their nutritional patterns, lifestyle and attitudes towards treatment and prevention. ${ }^{30}$ Access to healthcare differs amongst male patients and female patients, as a result of their personal preconceptions. ${ }^{31}$ Hi-tech and rapid remedies are usually pursued by men in contrast to the extensive sociocultural therapies pursued by female patients. ${ }^{31}$ It is believed that the sociocultural female nature permits an escape from financial and societal drawbacks, whereas the masculine nature of males prompts the search for care that warrants a comprehensive speedy recuperation and lower economic burden. ${ }^{31}$ In addition, health-seeking behaviour may be higher for women compared to men in South Africa, particularly with respect to chronic diseases. ${ }^{32}$ Hence, it is possible that sociocultural and socioeconomic factors combined with spiritual beliefs and semantics are instrumental in understanding the bolder health-seeking behaviour represented by the higher percentage of women in our sample.

African data for gender distribution in T2DM have reported conflicting results. An increased prevalence amongst male patients was reported from studies in Tunisia, Egypt, Sudan, Cameroon and rural Tanzania, ${ }^{14,33,34,35}$ whilst prevalence was greater amongst female patients in South Africa (Durban), Mali, Cameroon and Sudan ${ }^{14,34,36}$ with an equal gender distribution reported from South Africa (Cape Town), Tanzania and Sudan. . $^{1530,36}$ 
Recent reports suggest that diabetics are predisposed to one or more comorbidity. ${ }^{37}$ A study conducted in 12 primary healthcare clinics in South Africa revealed a $79 \%$ prevalence of hypertension, whilst complications related to the eyes, feet and kidneys were $8.2 \%, 6.5 \%$ and $21.4 \%$ respectively. ${ }^{34}$ Data on comorbidities-linked to eyes, feet and kidneys were not available for this study as we were limited by the hospital-outpatient register. T2DM is reported as the seventh leading cause for the risk of increased infections, morbidity and mortality in South Africa ${ }^{24}$ and accounted for approximately 68000 deaths in 2013. ${ }^{5}$ However, this may be a significant underestimation, when considering the mortality from complications or comorbidity associated with DM. The high prevalence of hypertension (77.9\%) amongst patients should be highlighted, particularly that $80 \%$ women $(2451 / 3072)$ and $40 \%$ of all early onset diabetics (176/441) presented with hypertension. Our data are in contrast with earlier data from ref. 38, which suggested that hypertension affects $20 \%-60 \%$ of patients with T2DM, depending on obesity, ethnicity and age. It would appear that morbidity associated with hypertension, which is a common complication of T2DM, is increasing. This is of concern as the combination of DM and hypertension increases the risk of premature cardiovascular disease. ${ }^{38}$

Regression analyses demonstrated that female patients with T2DM were at significantly higher risk of presenting with hypertension $(\mathrm{OR}=1.44,95 \% \mathrm{CI}: 1.20-1.71, p<0.001)$ and arthritis but had a lower risk for cardiovascular problems compared to male patients $(\mathrm{OR}=0.67,95 \% \mathrm{CI}$ : $0.54-0.83$, $p<0.001)$. Likewise, the risk of cardiovascular disease (CVD), especially myocardial infarction, was also shown to be greater in a Danish cohort of female diabetic patients below 50 years..$^{39}$ More recently, female patients already diagnosed with T2DM develop a greater risk to acquire CVD, with overweight/obesity and postmenopausal women being at a higher risk. ${ }^{40}$ We also found that the prevalence of comorbidities was highest amongst Indians regardless of age and sex, in contrast to other race groups. Regression data further demonstrated that Indians with T2DM were predisposed to a higher risk for cardiovascular problems and asthma, but had a lower risk for epilepsy, arthritis and mental health issues compared to Africans. The $12.5 \%$ crude prevalence of T2DM in KZN was higher than the $9.2 \%$ national prevalence, which could be because of the large population of Indians (South Asian) living in KZN in contrast to other cities in SA, suggestive of a possible genetic predisposition to T2DM. ${ }^{5,15}$ Our data suggest that comorbidities increase significantly with age, which is in agreement with the study made by Uddin et al. ${ }^{41}$ Uddin and co-workers reported that $\mathrm{T} 2 \mathrm{DM}+1$ and $\mathrm{T} 2 \mathrm{DM}+2$ comorbidities were higher in male patients, whilst $\mathrm{DM}+3$ comorbidities were higher amongst female patients. ${ }^{41}$ However, our data showed significantly more female patients with $\mathrm{T} 2 \mathrm{DM}+1, \mathrm{~T} 2 \mathrm{DM}+2, \mathrm{~T} 2 \mathrm{DM}+3$ comorbidities $(p<0.05)$, which was suggestive that sex, ethnicity and age are critical determinants associated with the prevalence of T2DM and comorbidities.
Demographic data are essential in advancing the precision in the prediction of incidence, complications, morbidity and mortality related to T2DM. ${ }^{20}$ Data obtained from such analyses will accurately inform healthcare systems and enhance the development of tracking proficiencies required for reducing the incidence of DM and associated comorbidities. To date, the management of T2DM following a uniform treatment algorithm is usually associated with poor treatment adherence and the subsequent development of complications. ${ }^{42}$ Recent data suggest that some medications may serve dual purposes, for example, the use of metformin (a first line treatment for T2DM) reduced asthma-related outcomes in patients who presented with T2DM and asthma concurrently, ${ }^{43}$ whilst hydroxychloroquine (commonly used antirheumatic medication) demonstrated hypoglycaemic effects. ${ }^{44}$ The healthcare system in SA, which is already burdened by the HIV/TB epidemic coupled with increasing infectious diseases, could be further constrained by the increasing prevalence of diabetes and comorbidities. Various studies conducted in South Africa, Nigeria, Ghana, Cameroon and Tanzania confirm both the increase in prevalence and the changing epidemiology of diabetes complications; ${ }_{17}^{17}$ however, these data are over 15 years old. Arising from these predictions, it is crucial to re-evaluate the extent of the problem so that healthcare resources may be appropriately allocated. In order to gain better control of chronic complications, treatment and management for T2DM and complications, interventions should primarily target the highly prevalent populations with chronic complications including older diabetic patients and those with a long history of diabetes.

A limitation of this study is that as this study was hospitalbased, the results only apply for diabetics requiring primary level of healthcare rather than representing the total population of diabetics which include people able to access medical aid and private healthcare. In addition, hospital outpatient records did not include information about microvascular conditions that are a significant comorbidity related to diabetes-linked mortality and morbidity.

\section{Conclusion}

The variation of complications with age, gender and ethnicity amongst patients with a T2DM diagnosis all point to a need for flexible and adaptive approaches for the prevention and management of T2DM cases in order to allocate medical resources efficiently and according to the true local burden of disease because of T2DM complications. Findings arising from this study are specific to the Indian and African populations in KZN, but may be aligned with some from other provinces in South Africa. Future research evaluating long-term clinical outcomes in high-risk sub-populations, based on ethnicity, age and underlying comorbid conditions, is warranted for more effective management. Furthermore, the disparities in comorbidities linked with T2DM based on ethnicity warrant the exploration of precision medicine amongst indigenous populations in 
South Africa. The use of precision medicine in stratifying diabetics into groups based on the molecular and genetic biomarkers as well as clinical characteristics has been explored to optimise therapeutic outcomes, with the intention of providing recommendations that target groups rather than individual patients. This may be an exploratory option for SA where the increasing prevalence of T2DM, coupled with the attributable burden of associated comorbidity, has the potential to create significant pressure on the healthcare system.

\section{Acknowledgements}

The authors wish to thank the staff of RK Khan Hospital for their assistance during data collection.

\section{Competing interests}

The authors declare that they have no financial or personal relationships that may have inappropriately influenced them in writing this article.

\section{Authors' contributions}

L.C. was the primary investigator, and N.G., G.M.G. and P.R. conceptualised and supervised the study. All authors contributed to the preparation of this manuscript.

\section{Funding information}

This work was supported by the Durban University of Technology under grant 112/19.

\section{Data availability}

The datasets generated and/or analysed during the current study are available from the corresponding author on reasonable request.

\section{Disclaimer}

The views and opinions expressed in this article are those of the authors and do not necessarily reflect the official policy of any affiliated agency of the authors.

\section{References}

1. Cho N, Shaw JE, Karuranga S, et al. IDF Diabetes Atlas: Global estimates of diabetes prevalence for 2017 and projections for 2045. Diabetes Res Clin Pract. 2018;138:271-281. https://doi.org/10.1016/j.diabres.2018.02.023

2. Shaw JE, Sicree RA, Zimmet PZ. Global estimates of the prevalence of diabetes for 2010 and 2030. Diabetes Res Clin Pract. 2010;87(1):4-14. https://doi. org/10.1016/j.diabres.2009.10.007

3. Harries $A D$, Lin $Y$, Satyanarayana $S$, et al. The looming epidemic of diabetes associated tuberculosis: Learning lessons from HIV-associated tuberculosis. Int Tubercul Lung Dis. 2011;15(11):1436-1445. https://doi.org/10.5588/ijtld.11.0503

4. STATS SA. Mortality and causes of death in South Africa, 2016: Findings from death notification [homepage on the Internet]. 2019 [cited 2020 Jan 04]. Available from: https://www.statssa.gov.za/publications/P03093/P030932016.pdf

5. Sahadew N, Singaram VS, Brown S. Distribution, incidence, prevalence and default of patients with diabetes mellitus accessing public healthcare in the 11 districts of KwaZulu-Natal, South Africa. S Afr Med J. 2016;106(4):389-393. https://doi. org/10.7196/SAMJ.2016.v106i4.10143

6. Garduño-Diaz SD, Khokhar S. Prevalence, risk factors and complications associated with type 2 diabetes in migrant South Asians. Diabetes Metabol Res Rev. 2012;28(1):6-24. https://doi.org/10.1002/dmrr.1219
7. Mbanya JC, Assah FK, Saji J, Atanga EN. Obesity and type 2 diabetes in Sub-Sahara Africa. Curr Diabetes Rep. 2014;14(7):501. https://doi.org/10.1007/s11892-0140501-5

8. Pheiffer C, Pillay-van Wyk V, Joubert JD, Levitt N, Nglazi MD, Bradshaw D. The prevalence of type 2 diabetes in South Africa: A systematic review protocol. BM Open. 2018;8(7):e021029. https://doi.org/10.1136/bmjopen-2017-021029

9. Bertram MY, Jaswal AV, Van Wyk VP, Levitt NS, Hofman KJ. The non-fatal disease burden caused by type 2 diabetes in South Africa, 2009. Global Health Action. 2013;6(1):19244. https://doi.org/10.3402/gha.v6i0.19244

10. Elbagir MN, Eltom MA, Elmahadi EM, Kadam IM, Berne C. A population-based study of the prevalence of diabetes and impaired glucose tolerance in adults in northern Sudan. Diabetes Care. 1996;19(10):1126-1128. https://doi.org/10.2337/ diacare.19.10.1126

11. Levitt NS, Katzenellenbogen JM, Bradshaw D, Hoffman MN, Bonnici F. The prevalence and identification of risk factors for NIDDM in urban Africans in Cape Town, South Africa. Diabetes Care. 1993;16(4):601-607. https://doi.org/10.2337/ diacare.16.4.601

12. Mollentze WF, Moore AJ, Steyn AF, et al. Coronary heart disease risk factors in a rural and urban Orange Free State black population. S Afr Med J. 1995;85(2): rural and 96.

13. Ahren B, Corrigan CB. Prevalence of diabetes mellitus in north-western Tanzania. Diabetologia. 1984;26(5):333-336. https://doi.org/10.1007/BF00266032

14. Elbagir MN, Eltom MA, Elmahadi EM, Kadam IM, Berne C. A high prevalence of diabetes mellitus and impaired glucose tolerance in the Danagla community in northern Sudan. Diabetic Med. 1998;15(2):164-169. https://doi.org/10.1002/ (SICI)1096-9136(199802)15:2\%3C164::AID-DIA536\%3E3.0.CO;2-A

15. Omar MK, Seedat MA, Motala AA, Dyer RB, Becker P. The prevalence of diabetes mellitus and impaired glucose tolerance in a group of urban South African blacks. S Afr Med J. 1993;83(9):641-643.

16. King H, Aubert RE, Herman WH. Global burden of diabetes, 1995-2025: Prevalence, numerical estimates, and projections. Diabetes Care. 1998;21(9):1414-1431. https://doi.org/10.2337/diacare.21.9.1414

17. Motala AA, Omar MA, Pirie FJ. Epidemiology of type 1 and type 2 diabetes in Africa. J Cardiovasc Risk. 2003;10(2):77-83. https://doi.org/10.1177/174182670 301000202

18. Waters KM, Stram DO, Hassanein MT, et al. Consistent association of type 2 diabetes risk variants found in europeans in diverse racial and ethnic groups. PLoS Genet. 2010;6(8):e1001078. https://doi.org/10.1371/journal.pgen.1001078

19. Gujral UP, Pradeepa R, Weber MB, Narayan KV, Mohan V. Type 2 diabetes in South Asians: Similarities and differences with white Caucasian and other populations. Ann New York Acad Sci. 2013;1281(1):51. https://doi.org/10.1111/ j.1749-6632.2012.06838.x

20. Pastakia SD, Pekny CR, Manyara SM, Fischer L. Diabetes in sub-Saharan Africafrom policy to practice to progress: Targeting the existing gaps for future care for diabetes. Diabetes Metab Syndr Obes. 2017;10:247-263. https://doi. org/10.2147/DMSO.S126314

21. Barendse S, Singh $\mathrm{H}$, Frier BM, Speight J. The impact of hypoglycaemia on quality of life and related patient-reported outcomes in Type 2 diabetes: A narrative review. Diabet Med. 2012;29(3):293-302. https://doi.org/10.1111/j.14645491.2011.03416.x

22. Boehme MW, Buechele G, Frankenhauser-Mannuss J, et al. Prevalence, incidence and concomitant co-morbidities of type 2 diabetes mellitus in South Western Germany-a retrospective cohort and case control study in claims data of a large statutory health insurance. BMC Publ Health. 2015;15(1):855. https://doi. statutory health insurance. BMC
org/10.1186/s12889-015-2188-1

23. Mutyambizi C, Chola L, Groot W, Pavlova M, Labadarios D, Hongoro C. The extent and determinants of diabetes and cardiovascular disease comorbidity in South Africa-results from the South African National Health and Nutrition Examination Survey (SANHANES-1). BMC Publ Health. 2017;17(1):745. https://doi. org/10.1186/s12889-017-4792-8

24. Stokes A, Berry KM, Mchiza Z, et al. Prevalence and unmet need for diabetes care across the care continuum in a national sample of south African adults: Evidence from the SANHANES-1, 2011-2012. PLoS One. 2017;12(10):e0184264. https:// doi.org/10.1371/journal.pone.0184264

25. Schram MT, Sep SJ, Van der Kallen CJ, et al. The Maastricht study: An extensive phenotyping study on determinants of type 2 diabetes, its complications and its comorbidities. Eur J Epidemiol. 2014;29(6):439-451. https://doi.org/10.1007/ s10654-014-9889-0

26. Chawla A, Chawla R, Jaggi S. Microvasular and macrovascular complications in diabetes mellitus: Distinct or continuum? Indian J Endocrinol Metabol. 2016;20(4):546. https://doi.org/10.4103/2230-8210.183480

27. Mayosi BM, Flisher AJ, Lalloo UG, Sitas F, Tollman SM, Bradshaw D. The burden of non-communicable diseases in South Africa. Lancet. 2009;374(9693):934-947. https://doi.org/10.1016/S0140-6736(09)61087-4

28. KZN Department of Health. History of RK Khan Hospital [homepage on the Internet]. 2019 [cited 2020 Jan 04]. Available from: www.kznhealth.gov.za/ RKKhan/history1.htm

29. Webb EM, Rheeder P, Van Zyl DG. Diabetes care and complications in primary care in the Tshwane district of South Africa. Prim Care Diabetes. 2015;9(2):147-154. https://doi.org/10.1016/j.pcd.2014.05.002

30. Kautzky-Willer A, Harreiter J, Pacini G. Sex and gender differences in risk, pathophysiology and complications of type 2 diabetes mellitus. Endocr Rev. 2016;37(3):278-316. https://doi.org/10.1210/er.2015-1137 
31. Das M, Angeli F, Krumeich AJ, Van Schayck OC. The gendered experience with respect to health-seeking behaviour in an urban slum of Kolkata, India. with respect to health-seeking behaviour in an urban slum of Kolkata, India. Int J Equil

32. Mugisha JO, Schatz EJ, Randell M, et al. Chronic disease, risk factors and disability in adults aged 50 and above living with and without HIV: Findings from the wellbeing of older people study in Uganda. Global Health Action. 2016;9(1):31098. https://doi.org/10.3402/gha.v9.31098

33. McLarty DG, Kitange HM, Mtinangi BL, et al. Prevalence of diabetes and impaired glucose tolerance in rural Tanzania. The Lancet. 1989;333(8643):871-875. https:// doi.org/10.1016/S0140-6736(89)92866-3

34. Mbanya JC, Ngogang J, Salah JN, Minkoulou E, Balkau B. Prevalence of NIDDM and impaired glucose tolerance in a rural and an urban population in Cameroon. Diabetologia. 1997;40(7):824-829. https://doi.org/10.1007/s0012 50050755

35. Herman WH, Ali MA, Aubert RE, et al. Diabetes mellitus in Egypt: Risk factor and prevalence. Diabet Med. 1995;12(12):1126-1131. https://doi.org/10.1111/ j.1464-5491.1995.tb00432.x

36. Druss BG, Marcus SC, Olfson M, Tanielian T, Elinson L, Pincus HA. Comparing the national economic burden of five chronic conditions. Health Aff. 2001;20(6):233-241. https://doi.org/10.1377/hlthaff.20.6.233

37. Wolff JL, Starfield B, Anderson G. Prevalence, expenditures, and complication of multiple chronic conditions in the elderly. Arch Intern Med. 2002;162(20): 2269-2276. https://doi.org/10.1001/archinte.162.20.2269
38. McLean DL, McAlister FA, Johnson JA, et al. A randomized trial of the effect of community pharmacist and nurse care on improving blood pressure management in patients with diabetes mellitus: Study of Cardiovascular Risk Intervention in patients with diabetes mellitus: Study of Cardiovascular Risk Intervention
by Pharmacists-Hypertension (SCRIP-HTN). Arch Intern Med. 2008;168(21): 2355-2361. https://doi.org/10.1001/archinte.168.21.2355

39. Lindhardsen J, Ahlehoff $\mathrm{O}$, Gislason $\mathrm{GH}$, et al. The risk of myocardial infarction in rheumatoid arthritis and diabetes mellitus: A Danish nationwide cohort study. Ann Rheum Dis. 2011;70(6):929-934. https://doi.org/10.1136/ard.2010.143396

40. Al-Salameh A, Chanson P, Bucher S, Ringa V, Becquemont L. Cardiovascular disease in type 2 diabetes: A review of sex-related differences in predisposition and prevention. Mayo Clin Proc. 2019;94(2):287-308. https://doi.org/10.1016/j. mayocp.2018.08.007

41. Uddin F, Zaheer S, Shafique K. Age and gender-related variations in comorbidities among diabetes patients - A community-based cross-sectional study. Diabetes. 2018; 67(1): 2395. https://doi.org/10.2337/db18-2395-PUB

42. jXie F, Chan JC, Ma RC. Precision medicine in diabetes prevention, classification and management. J Diabetes Investig. 2018;9(5):998-1015. https://doi. org/10.1111/jdi.12830

43. Li CY, Erickson SR, Wu CH. Metformin use and asthma outcomes among patients with concurrent asthma and diabetes. Respirology. 2016;21(7):1210-1218. https://doi.org/10.1111/resp.12818

44. Wasko MC, Hubert HB, Lingala VB, et al. Hydroxychloroquine and risk of diabetes in patients with rheumatoid arthritis. JAMA. 2007;298(2):187-193. https://doi. org/10.1001/jama.298.2.187 